\title{
Dynamic Epidemiology of Acute Viral Hepatitis in Japan
}

\author{
Koji Yano ${ }^{a, b}$ Yoko Tamada ${ }^{b}$ Hiroshi Yatsuhashib ${ }^{b}$ Atsumasa Komorib \\ Seigo Abiru ${ }^{b}$ Kiyoaki Ito ${ }^{a}$ Naohiko Masaki ${ }^{a}$ Masashi Mizokamia \\ Hiromi Ishibashi ${ }^{b}$ Japan National Hospital Acute Hepatitis Study Group \\ ${ }^{a}$ Research Center for Hepatitis and Immunology, International Medical Center of Japan, Kohnodai Hospital, Chiba, \\ and ${ }^{b}$ Clinical Research Center, NHO National Nagasaki Medical Center, Nagasaki, Japan
}

\section{Key Words}

Acute hepatitis · Epidemiology • Hepatitis B virus genotype A • Hepatitis E

\begin{abstract}
The epidemiology of acute viral hepatitis (AVH) is dynamic and affected by many factors including hygiene, socioeconomic status and vaccination coverage. A total of 4,302 cases of $\mathrm{AVH}$ were sequentially enrolled in this nationwide study between 1980 and 2008. Of the cases of AVH, acute hepatitis A (AHA) accounted for 1,583 (36.8\%), acute hepatitis B (AHB) for $1,197(27.8 \%)$, acute hepatitis $C$ (AHC) for $359(8.3 \%)$, and non- $A$, non-B and non-C (non-ABC) for 1,163 (27.0\%). Between 1980 and 1995, the proportions of AHA, AHB, AHC and non- $A B C$ were approximately $40,25,10$ and $25 \%$; between 1996 and 2003, they were approximately $30,30,10$ and $30 \%$, and this shifted to approximately $10,40,10$ and $40 \%$ in the last 5 years. The number of AHB caused by genotype A, which is not indigenous to Japan, was 6.0\% between 1991 and 1996 but has been markedly increasing since 2000, to reach $52 \%$ in 2008. Autochthonous acute hepatitis E (AHE) accounted for $10-15 \%$ of non-ABC hepatitis after 2002. The etiology of $A V H$ in Japan has been drastically changing. $A$ marked increase of AHB genotype A and constant occurrence of autochthonous AHE require attention, and necessary measures should be taken.
\end{abstract}

Copyright $\odot 2010$ S. Karger AG, Basel (c) 2010 S. Karger AG, Basel

0300-5526/10/0531-0070\$26.00/0

Fax +41613061234

E-Mail karger@karger.ch

www.karger.com
Accessible online at:

www.karger.com/int

\section{Introduction}

Acute viral hepatitis $(\mathrm{AVH})$ is caused by infection with any hepatitis virus, of which the 3 most commonly identified in Japan are hepatitis A (HAV), hepatitis B (HBV), and hepatitis $\mathrm{C}(\mathrm{HCV})$. In addition, after excluding other known non-hepatitis viruses, such as Epstein-Barr virus, herpes simplex virus and other causes of acute hepatic injury including autoimmune hepatitis and alcoholic hepatitis, non-ABC acute hepatitis can be categorized. All of these unrelated viruses can produce an acute illness characterized by nausea, malaise, abdominal pain and jaundice [1]. Epidemiology of acute hepatitis is dynamic and affected by many factors including hygiene, socioeconomic status, prevalence of other diseases such as HIV infection, and coverage of available vaccination $[1,2]$. A longitudinal study of surveillance is usually difficult to conduct and rare. In this article, we show the results of our surveillance study which has been conducted for almost 3 decades.

\section{Materials and Methods}

A mini-sentinel surveillance involving 28 liver centers of national hospitals located nationwide and which cover almost the whole of Japan has been conducted since 1980. All cases of AVH which were admitted to one of our hospitals have been sequential-

Koji Yano, MD, PhD

Research Center for Hepatitis and Immunology

International Medical Center of Japan, Kohnodai Hospital

1-7-1 Kohnodai, Ichikawa, Chiba 272-0827 (Japan)

Tel. +81 473723 501, Fax +81 473754 766, E-Mail kyano-kkr@umin.ac.jp 
Fig. 1. Trends of AVH in Japan (1980$2008, \mathrm{n}=4,302)$.

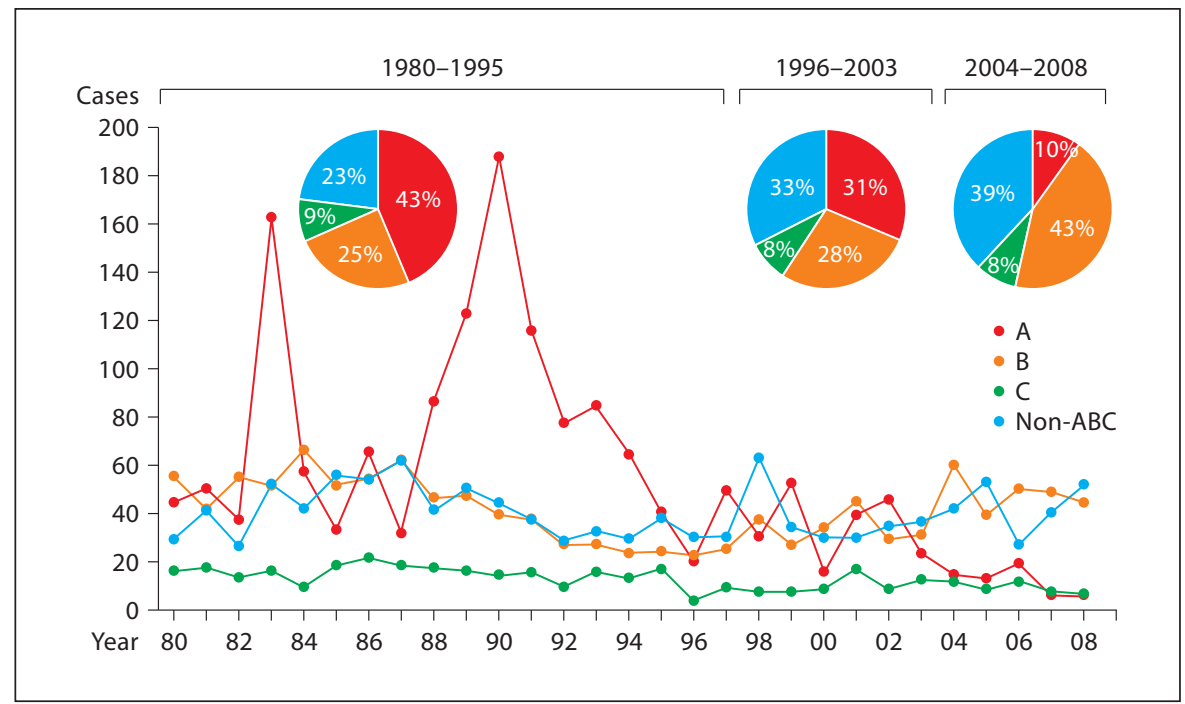

ly enrolled to the study, and sera taken on admission were stored for further analysis. There were some, but only minor changes in the member hospitals due to personnel transfer and/or elimination and consolidation of hospitals during the observation period.

\section{Clinical Case Definition}

Acute hepatitis was defined as acute illness with (1) discrete onset of symptoms (e.g. nausea, anorexia, fever or malaise) and (2) jaundice or elevated serum aminotransferase and/or total bilirubin levels.

The laboratory criteria for confirming each type of AVH were as follows: (1) acute hepatitis A (AHA): positivity for immunoglobulin M (IgM) antibody to hepatitis A virus (anti-HAV); (2) acute hepatitis $\mathrm{B}$ (AHB): positivity for IgM antibody to hepatitis $\mathrm{B}$ core antigen (anti-HBc) or hepatitis B surface antigen (HBsAg) (3) acute hepatitis C (AHC): positivity for RT-PCR for HCV RNA, and either anti-HCV negativity at the onset of disease or significant increase of anti-HCV in the assay 2 weeks after onset.

Exclusion criteria were as follows: (1) involvement of non-hepatitis viruses, including Epstein-Barr virus, cytomegalovirus, parvovirus and herpes virus; (2) involvement of other etiologies such as autoimmune hepatitis, drug-induced hepatitis, and (3) alcoholic liver diseases. After excluding such types of liver dysfunction, the 4 th category of non-ABC hepatitis was made.

\section{Data Collection}

In this survey, patients' data and serum samples were collected on an annual basis and stored at the National Nagasaki Medical Center until they were used for analysis. After 2005, all patients' written informed consent for enrollment in this study was obtained.

\section{RT-PCR and Sequencing}

Samples that were serologically confirmed for AHB or acute hepatitis E (AHE) were further subjected to DNA or RNA testing by means of PCR and RT-PCR, respectively. Amplification and sequencing of appropriate regions were performed by the methods described elsewhere. Briefly, total RNA or DNA was extract- ed from the patient's serum sample. Detection of hepatitis virus genome was performed by PCR with primers derived from wellconserved genomic areas. Sequences were compared with those from isolates from various origins. Phylogenetic trees were constructed by neighbor-joining method.

\section{Results}

\section{Trends of AVH in Japan}

A total of 4,302 cases are the subject of this study. In total, throughout the study period (1980-2008) AHA accounted for 1,583 cases (37\%), AHB for 1,197 (28\%), AHC for 359 (8\%) and non-ABC hepatitis for 1,163 (27\%). The period between 1980 and 1995 when AHA was apparently predominant among viral hepatitis can be called the AHA dominant phase. During the following 8 years (1996-2003), however, the proportions of AHA, AHB, $\mathrm{AHC}$ and non-ABC hepatitis changed to $31,28,8$ and $33 \%$, respectively. This phase is characterized by even distribution of AHA, AHB and non-ABC hepatitis. Furthermore, the proportions of $\mathrm{AHA}, \mathrm{AHB}, \mathrm{AHC}$ and non- $\mathrm{ABC}$ hepatitis in the last 5 years (2004-2008) were 10, 43, 8 and $39 \%$, respectively. Apparently, these changes in trend of hepatitis were caused by a major decrease of AHA incidence (fig. 1).

\section{Genotype Shifting of $A H B$}

Genotype analyses for AHB cases were done on 498 samples (1991-2008). Figure 2a shows the proportions of genotypes. Respectively, genotypes A, B and C accounted for 23\% (115), 8.6\% (43) and 67.5\% (336) of AHB during 

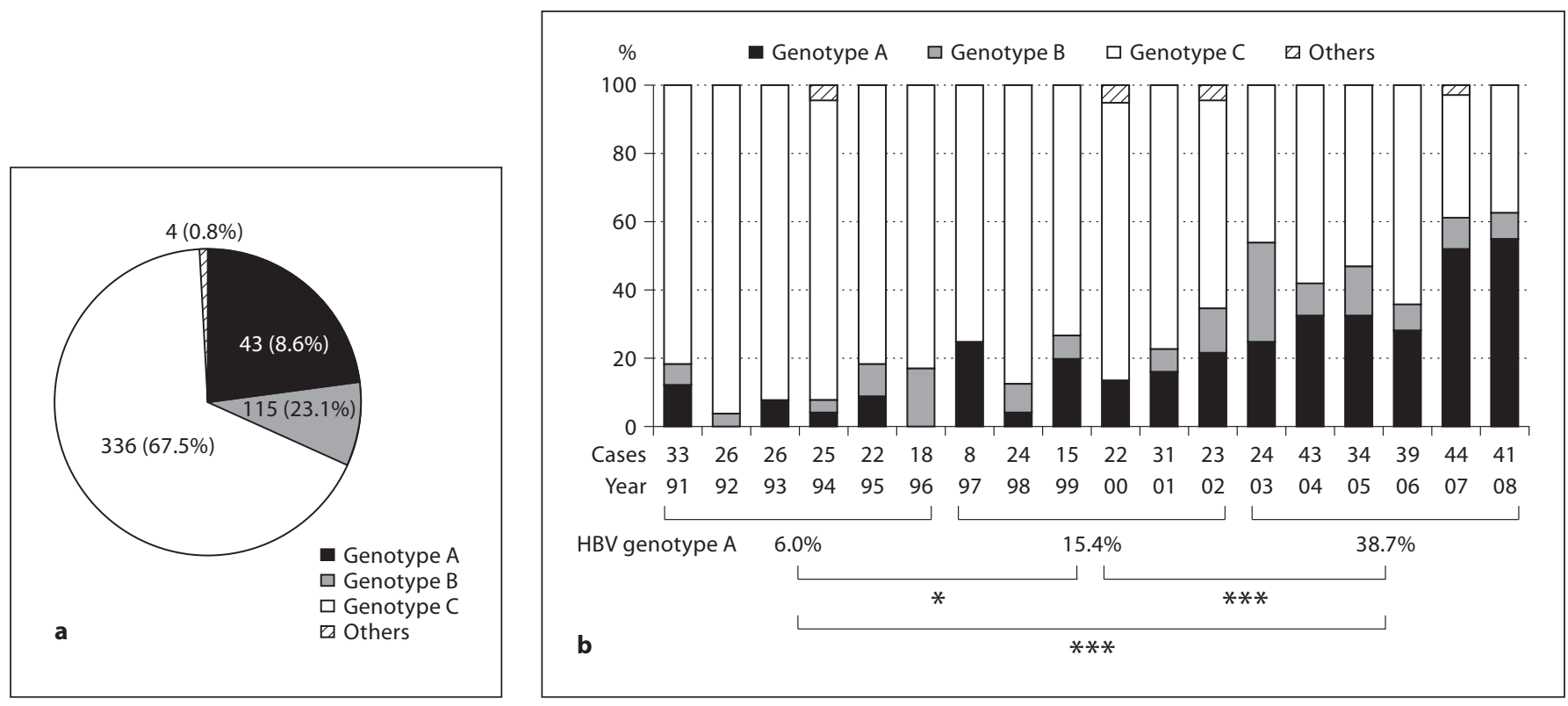

Fig. 2. a Genotype change in AVB (1991-2008, $\mathrm{n}=498)$. b Trends of HBV genotypes (1991-2008). Note that HBV genotype A has increased in the course of the observation period. ${ }^{*} \mathrm{p}<0.05 ;{ }^{* *} \mathrm{p}<0.001$.

the period, whereas 1 case $(0.2 \%)$ each of genotypes $\mathrm{D}, \mathrm{E}$, $\mathrm{G}$ (co-infection with genotype $\mathrm{A}$ ) and $\mathrm{H}$ was found. The trend of genotypes of AHB is shown in figure $2 \mathrm{~b}$. HBV genotype A was confirmed in 9 of 150 cases $(6.0 \%)$ in phase 1 (1991-1996), 19 of 123 (15.4\%) in phase 2 (19972002) and 87 of 225 (38.7\%) in phase 3 (2002-2008). An apparent increment of AHB by HBV genotype A proportion is observed ( $\mathrm{p}<0.05$, 1st vs. 2nd phase; $\mathrm{p}<0.0001$, 1 st vs. 3 rd and 2 nd vs. 3 rd phases). In contrast, HBV genotype B was observed in 9 of 150 cases (6.0\%) in phase 1,9 of $123(15.4 \%)$ in phase 2 and 26 of 225 (11.6\%) in phase 3 . There was no significant difference among the frequency of AHB by HBV genotype B in the 3 phases. Characteristics of AHB by HBV genotype A include male dominance $(94.8 \%$ for genotype A, $76.7 \%$ for B and $56.0 \%$ for C; $\mathrm{p}<0.001)$, higher total bilirubin $(10.1 \pm 7.9 \mathrm{mg} / \mathrm{dl}$ for genotype A, $8.1 \pm 7.6 \mathrm{mg} / \mathrm{dl}$ for B and $6.9 \pm 5.9 \mathrm{mg} / \mathrm{dl}$ for $C$; $p<0.001)$, lower frequency of severe cases $(3.5 \%$ for $\mathrm{A}, 11.0 \%$ for $\mathrm{B}$ and $8.3 \%$ for $\mathrm{C} ; \mathrm{p}<0.05$ ), and higher rate of chronicity ( $3 \%$ for $\mathrm{A}$ and $0 \%$ for both B and C; p < 0.05).

\section{Domestic or Imported Hepatitis E in Japan}

In the 1,163 cases of non-ABC hepatitis, $896(77.0 \%)$ samples were available for anti-hepatitis E (HEV) analysis. Of the 896 cases, 8 were positive for anti-HEV IgM alone, 78 were positive for anti-HEV IgG alone, and 44 cases tested positive for both anti-HEV IgM and IgG. Based upon studies on specificity tests (data not shown), the 44 cases $(4.9 \%)$ which were positive for both antiHEV IgM and IgG were given a final diagnosis of AHE. Among the 44 samples, RT-PCR for HEV was performed for 30 samples which all showed positive. Eleven cases had a history of international travel, whereas 20 did not. Travel history was not confirmed in the remaining 13 patients, who probably acquired HEV infection locally. Phylogenetic analysis revealed that all but 1 (genotype 4) domestic infections were caused by HEV genotype 3, whereas imported infections were caused by either genotype 1,3 or 4 .

Figure 3 shows the trend of non- $\mathrm{ABC}$ and hepatitis $\mathrm{E}$ that had been buried in non-ABC from 1980-2008 in this study. In Japan, which has been believed to be a non-endemic country for HEV, AHE occurred sporadically as early as the 1980s. Although the number of hepatitis $\mathrm{E}$ (1-6 cases per year) and the ratio to non-A, B, C and E hepatitis (0-14.5\%) are not very high and insignificant, the occurrence of hepatitis E became constant after 2002. Hepatitis E constituted 11.0\% (25/228) of non-ABC hepatitis after 2002. All patients with AHE recovered, and none of the cases showed prothrombin time less than $40 \%$. 
Fig. 3. Trends of non-ABC hepatitis (1980 2008, n = 895). Bars indicate numbers of non-ABC hepatitis in each year. Closed bars within, indicate absolute numbers of $\mathrm{AHE}$, and the line plot indicates the ratio of $\mathrm{AHE}$ to non-ABC hepatitis.

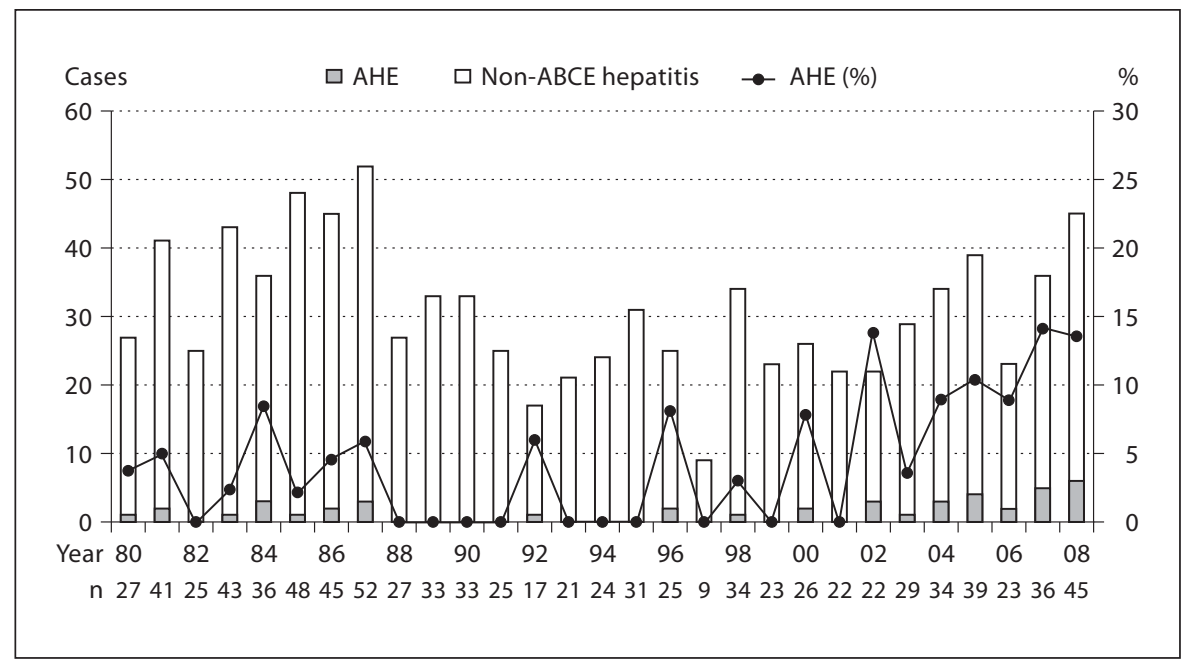

\section{Discussion}

Despite being notifiable infectious diseases, very limited information has been available on the epidemiology of AVH in Japan. Under-reporting of cases has been linked to lack of awareness of the reporting system by medical practitioners and a rather complex process of notification. This study, which is a nationwide longitudinal survey carried out over a long period, provides reliable data on trends of AVH in Japan.

In this study, $\mathrm{AHV}$ is classified into 4 categories, namely, AHA, AHB, AHC and non-ABC hepatitis. Other etiologies of AVH, such as Epstein-Barr virus, cytomegalovirus, and herpes simplex virus-associated hepatitis, were excluded to focus on the epidemiology of 'hepatitis virus'. Accordingly, the category non-ABC hepatitis may consist of undiscovered or submerged types of hepatitis, such as AHE which had been paid little attention as a cause of domestic AVH in most industrialized countries, including Japan, until recently.

The overview of trends among all 4,302 cases in chronological fashion reveals that the cause of hepatitis in Japan has been drastically changed during the past 3 decades. This change is largely due to a major decrease of AHA, probably because of improvements in hygienic conditions in this country.

In connection with this decrease of AHA incidence, a marked decrease of anti-hepatitis A prevalence among the healthy population has been observed. More than $99 \%$ of individuals who were under 50 years old were sensitive to hepatitis A in 2006 (unpubl. observation). This may paradoxically rouse a debate over the need for vaccination in this low-endemic country. In fact, many out- breaks have been observed in low-endemic countries [3, 4], which can be linked to imported foods.

There was a remarkable increase in AHB by HBV genotype A from the 1st phase (1991-1996) to the 2nd (1997-2002) and 3rd (2003-2008) phases. This observation is consistent with previous reports [5-11]. Like other investigators, we observed an increase of HBV genotype A which had not been indigenous to Japan, probably because of a marked increase of immigration from countries where HBV genotype A is common. Taking into consideration that all AHB by HBV genotype A patients reported in our study were Japanese and most of them had neither travel histories nor contact with foreign people, it seems to be natural to speculate that original transmission had happened from foreign individuals to Japanese, and secondary spread from Japanese to other native individuals were carried out.

Clinical characteristics of AHB by genotype A is of particular importance. Our data indicate a milder, but prolonged course of AHB genotype A compared to genotype $\mathrm{B}$ or genotype $\mathrm{C}$. Although chronicity of HBV genotype A has been a matter of concern, the reported chronicity rate varies $[5,7,8]$. If $\mathrm{HBV}$ genotype $\mathrm{A}$ is prone to cause chronic infection in immunocompetent adults, the increase of such strains in acute hepatitis may change the picture of chronic infection in this country. Indeed, Matsuura et al. [12] reported that HBV genotype A in chronic hepatitis B between 2005 and 2006 was twice as frequent ( 3.5 vs. $1.7 \% ; \mathrm{p}=0.02$ ) as it was in their previous cohort between 2000 and 2001 [13]. A further study, especially a prospective one, is necessary to confirm the scenario. 
HEV is a major cause of acute hepatitis in many developing countries where AHE is an important public health concern. However, cases of sporadic AHE in people with no history of recent travel have been reported in developed regions such as North America, Europe, Japan and Australia [14-21]. The reporting of such infections together with the availability of more comprehensive molecular and serological data has led to the re-evaluation of HEV epidemiology and to the acceptance that autochthonous AHE is a clinical problem in developed countries [14]. Information on AHE in the non-ABC hepatitis population in Japan is limited, although there are many reports of sporadic or epidemic occurrence of AHE [2128]. The current study also showed the trend of AHE in Japan. AHE constituted 4.9\% (44/896) of non-ABC hepatitis. Although the number of AHE cases (1-6 cases per year) and its ratio to non- $\mathrm{ABC}$ hepatitis $(0-14.5 \%)$ are not very high and insignificant, the occurrence of AHE became constant after 2002. Surprisingly, AHE constituted as high as $11.0 \%$ (25/228) of non-ABC hepatitis after 2002. The clinical course was generally modest, and none of the patients showed a severe type of hepatitis, probably because most domestic cases were caused by HEV genotype 3 which has been implicated with milder clinical outcome compared with HEV genotype 4 [29-31]. This phenomenon may reflect the fact that our sentinels involve only a few institutes in Hokkaido where HEV genotype 4 is endemic. Nevertheless, the trend of AHE requires particular attention, because mode of transmission is still often unknown, even after taking very careful history of eating particular foods such as raw meat of deer, pigs and boars [29].

\section{Acknowledgment}

This study was partially supported by a grant-in-aid from the National Hospital Organization and from the Ministry of Health, Labor and Welfare of Japan.

\section{Disclosure Statement}

All authors do not have conflicts of interest to declare.

\section{Appendix}

Participating hospitals and physicians in charge in the Japan National Hospital Acute Hepatitis Study Group: NHO Nishi Sapporo Hospital, Hokkaido: Yukio Ohara, MD; NHO Dohoku Hospital, Hokkaido: Hideo Nishimura, MD; NHO Sendai Medical Center, Miyagi: Yutaka Mano, MD; NHO Matsumoto Medical Center, Nagano: Masakazu Kobayashi, MD; NHO Nishisaitamachuo Hospital, Saitama: Takeo Saoshiro, MD; Akira Saito, MD; NHO Tokyo Hospital, Tokyo: Michiyasu Yagura, MD; International Medical Center of Japan, Tokyo: Naohiko Masaki, MD; NHO Tokyo Medical Center, Tokyo: Masahiko Takahashi, MD; NHO Disaster Medical Center, Tokyo: Shigeki Hayashi, MD; NHO Yokohama Medical Center, Kanagawa: Tatsuji Komatsu, MD; NHO Sagamihara Hospital, Kanagawa: Yukio Watanabe, MD; Yoko Nakamura, MD; NHO Kanazawa Medical Center, Ishikawa: Hideo Morimoto, MD; Hajime Ohta, MD; NHO Nagoya Medical Center, Aichi: Masaaki Shimada, MD; NHO Kyoto Medical Center, Kyoto: Toshiki Komeda, MD; NHO Osaka-Minami Medical Center, Osaka: Taizo Hijioka, MD; NHO Osaka Medical Center, Osaka: Michio Kato, MD; Eiji Mita, MD; Noriyoshi Kuzushita, MD; NHO Yonago Medical Center, Tottori: Tetsuo Yamamoto, MD; NHO Okayama Medical Center, Okayama: Haruhiro Yamashita, MD; NHO Kure Medical Center, Hiroshima: Eiichi Takezaki, MD; Hiroshi Kohno, MD; Hirotaka Kono, MD; NHO Zentsuji Hospital, Kagawa: Shuji Oda, MD; Toru Hayashi, MD; NHO Kokura Medical Center, Fukuoka: Akihide Masumoto, MD; Takeaki Satoh, MD; NHO Kyusyu Medical Center, Fukuoka: Makoto Nakamuta, MD; NHO Oita Medical Center, Oita: Toyokichi Muro, MD; Kouichi Honda, MD; NHO Beppu Medical Center, Oita: Hironori Sakai, MD; NHO Kumamoto Medical Center, Kumamoto: Kazuhiro Sugi, MD; NHO Ureshino Medical Center, Saga: Michiaki Koga, MD; NHO Nagasaki Medical Center, Nagasaki: Koji Yano, MD; Yoko Tamada, MSc.

\section{References}

1 Daniels D, Grytdal S, Wasley A: Surveillance for acute viral hepatitis: United States, 2007. MMWR Surveill Summ 2009;58:1-27.

2 O'Connor JA: Acute and chronic viral hepatitis. Adolesc Med 2000;11:279-292.

-3 Lee D, Cho YA, Park Y, Hwang JH, Kim JW, Kim NY, Lee DH, Lee W, Jeong SH: Hepatitis A in Korea: epidemiological shift and call for vaccine strategy. Intervirology 2008;51:7074.
-4 Wheeler C, Vogt TM, Armstrong GL, Vaughan G, Weltman A, Nainan OV, Dato V, Xia G, Waller K, Amon J, Lee TM, Highbaugh-Battle A, Hembree C, Evenson S, Ruta MA, Williams IT, Fiore AE, Bell BP: An outbreak of hepatitis A associated with green onions. N Engl J Med 2005;353:890-897.
Kobayashi M, Ikeda K, Arase Y, Suzuki F, Akuta N, Hosaka T, Sezaki H, Yatsuji H, Kobayashi M, Suzuki Y, Watahiki S, Mineta R, Iwasaki S, Miyakawa Y, Kumada H: Change of hepatitis B virus genotypes in acute and chronic infections in Japan. J Med Virol 2008;80:1880-1884. 
6 Sugauchi F, Orito E, Ohno T, Tanaka Y, Ozasa A, Kang JH, Toyoda J, Kuramitsu T, Suzuki K, Tanaka E, Akahane Y, Ichida T, IzumiN, Inoue K, Hoshino H, IinoS, Yotsuyanagi H, Kakumu S, Tomita E, Okanoue T, Nishiguchi S, Murawaki Y, Hino K, Onji M, Yatsuhashi H, Sata M, Miyakawa Y, Ueda R, Mizokami M: Spatial and chronological differences in hepatitis B virus genotypes from patients with acute hepatitis B in Japan. Hepatol Res 2006;36:107-114.

-7 Yotsuyanagi H, Okuse C, Yasuda K, Orito E, Nishiguchi S, Toyoda J, Tomita E, Hino K, Okita K, Murashima S, Sata M, Hoshino H, Miyakawa Y, Iino S: Distinct geographic distributions of hepatitis B virus genotypes in patients with acute infection in Japan. J Med Virol 2005;77:39-46.

-8 Suzuki Y, Kobayashi M, Ikeda K, Suzuki F, Arfase Y, Akuta N, Hosaka T, Saitoh S, Kobayashi M, Someya T, Matsuda M, Sato J, Watabiki S, Miyakawa Y, Kumada H: Persistence of acute infection with hepatitis B virus genotype A and treatment in Japan. J Med Virol 2005;76:33-39.

-9 Kobayashi M, Suzuki F, Arase Y, Akuta N, Suzuki Y, Hosaka T, Saitoh S, Kobayashi M, Tsubota A, Someya T, Ikeda K, Matsuda M, Sato J, Kumada H: Infection with hepatitis B virus genotype A in Tokyo, Japan during 1976 through 2001. J Gastroenterol 2004;39: 844-850.

10 Suzuki F, Tsubota A, Arase Y, Suzuki Y, Akuta N, Hosaka T, Someya T, Kobayashi M, Saitoh S, Ikeda K, Kobayashi M, Matsuda M, Satoh J, Takagi K, Kumada H: Efficacy of lamivudine therapy and factors associated with emergence of resistance in chronic hepatitis $B$ virus infection in Japan. Intervirology 2003;46:182-189.

-11 Kobayashi M, Arase Y, Ikeda K, Tsubota A, Suzuki Y, Saitoh S, Kobayashi M, Suzuki F, Akuta N, Someya T, Matsuda M, Sato J, Takagi K, Miyakawa Y, Kumada H: Viral genotypes and response to interferon in patients with acute prolonged hepatitis B virus infection of adulthood in Japan. J Med Virol 2002; 68:522-528.

-12 Matsuura K, Tanaka Y, Hige S, Yamada G, Murawaki Y, Komatsu M, Kuramitsu T, Kawata S, Tanaka E, Izumi N, Okuse C, Kakumu S, Okanoue T, Hino K, Hiasa Y, Sata M, Maeshiro T, Sugauchi F, Nojiri S, Joh T, Miyakawa Y, Mizokami M: Distribution of hepatitis B virus genotypes among patients with chronic infection in Japan shifting toward an increase of genotype A. J Clin Microbiol 2009;47:1476-1483.
13 Orito E, Ichida T, Sakugawa H, Sata M, Horiike N, Hino K, Okita K, Okanoue T, Iino S, Tanaka E, Suzuki K, Watanabe H, Hige S, Mizokami M: Geographic distribution of hepatitis B virus (HBV) genotype in patients with chronic HBV infection in Japan. Hepatology 2001;34:590-594.

14 Dalton HR, Stableforth W, Thurairajah P, Hazeldine S, Remnarace R, Usama W, Farrington L, Hamad N, Sieberhagen C, Ellis V, Mitchell J, Hussaini SH, Banks M, Ijaz S, Bendall RP: Autochthonous hepatitis E in Southwest England: natural history, complications and seasonal variation, and hepatitis E virus IgG seroprevalence in blood donors, the elderly and patients with chronic liver disease. Eur J Gastroenterol Hepatol 2008; 20:784-790.

15 Heath TC, Burrow JN, Currie BJ, Bowden FJ, Fisher DA, Demediuk BH, Locarnini SA, Anderson DA: Locally acquired hepatitis E in the Northern Territory of Australia. Med J Aust 1995;162:318-319.

16 Ijaz S, Arnold E, Banks M, Bendall RP, Cramp ME, Cunningham R, Dalton HR, Harrison TJ, Hill SF, Macfarlane L, Meigh RE, Shafi S, Sheppard MJ, Smithson J, Wilson MP, Teo CG: Non-travel-associated hepatitis E in England and Wales: demographic, clinical, and molecular epidemiological characteristics. J Infect Dis 2005;192:11661172.

17 Mansuy JM, Peron JM, Abravanel F, Poirson H, Dubois M, Miedouge M, Vischi F, Alric L, Vinel JP, Izopet J: Hepatitis E in the south west of France in individuals who have never visited an endemic area. J Med Virol 2004;74: 419-424.

18 Meng XJ, Dea S, Engle RE, Friendship R, Lyoo YS, Sirinarumitr T, Urairong K, Wang D, Wong D, Yoo D, Zhang Y, Purcell RH, Emerson SU: Prevalence of antibodies to the hepatitis E virus in pigs from countries where hepatitis $\mathrm{E}$ is common or is rare in the human population. J Med Virol 1999;59:297-302.

19 Okamoto H, Takahashi M, Nishizawa T: Features of hepatitis E virus infection in Japan. Intern Med 2003;42:1065-1071.

20 Sainokami S, Abe K, Kumagai I, Miyasaka A, Endo R, Takikawa Y, Suzuki K, Mizuo H, Sugai Y, Akahane Y, Kiozumi Y, Yajima Y, Okamoto $\mathrm{H}$ : Epidemiological and clinical study of sporadic acute hepatitis E caused by indigenous strains of hepatitis E virus in Japan compared with acute hepatitis A. J Gastroenterol 2004;39:640-648.

21 Takahashi K, Iwata K, Watanabe N, Hatahara T, Ohta Y, Baba K, Mishiro S: Full-genome nucleotide sequence of a hepatitis E virus strain that may be indigenous to Japan. Virology 2001;287:9-12.
22 Matsuda H, Okada K, Takahashi K, Mishiro $S$ : Severe hepatitis E virus infection after ingestion of uncooked liver from a wild boar. J Infect Dis 2003;188:944.

23 Nagasaki F, Ueno Y, Mano Y, Igarashi T, Yahagi $\mathrm{K}$, Niitsuma $\mathrm{H}$, Okamoto $\mathrm{H}$, Shimosegawa T: A patient with clinical features of acute hepatitis E viral infection and autoimmune hepatitis. Tohoku J Exp Med 2005;206:173179.

24 Nakano Y, Yamauchi A, Yano T, Nakayama O, Sakai H, Nagasaka Y, Itaba S, Tabata Y, Sugiyama A: A diffuse outbreak of hepatitis $\mathrm{E}$ in Mie Prefecture, 2005. Jpn J Infect Dis 2006;59:136-138

25 Ohnishi S, Kang JH, Maekubo H, Takahashi K, Mishiro S: A case report: two patients with fulminant hepatitis E in Hokkaido, Japan. Hepatol Res 2003;25:213-218.

26 Suzuki A, Kumashiro R, Shirachi M, Kuroki M, Suzuki H, Tanikawa K, Sata M: Markedly prolonged jaundice from simultaneous infection with hepatitis E virus and leptospira. Kurume Med J 2003;50:155-159.

27 Tamada Y, Yano K, Yatsuhashi H, Inoue O, Mawatari F, Ishibashi H: Consumption of wild boar linked to cases of hepatitis E. J Hepatol 2004;40:869-870.

28 Tei S, Kitajima N, Ohara S, Inoue Y, Miki M, Yamatani T, Yamabe H, Mishiro S, Kinoshita Y: Consumption of uncooked deer meat as a risk factor for hepatitis E virus infection: an age- and sex-matched case-control study. J Med Virol 2004;74:67-70.

29 Abe T, Aikawa T, Akahane Y, Arai M, Asahina Y, Atarashi Y, Chayama K, Harada $\mathrm{H}$, Hashimoto N, Hori A, Ichida T, Ikeda H, Ishikawa A, Ito T, Kang JH, Karino Y, Kato H, Kato M, Kawakami M, Kitajima N, Kitamura T, Masaki N, Matsubayashi K, Matsuda H, Matsui A, Mizuo H, Mochida S, Moriyama M, Shibata M, Suzuki K, Takahashi K, Yamada G, Yamamoto K, Yamanaka T, Yamato H, Yano K, Mishiro S: Demographic, epidemiological, and virological characteristics of hepatitis E virus infections in Japan based on 254 human cases collected nationwide (article in Japanese, abstract in English). Kanzo 2006;2006:384-391.

>30 Mizuo H, Yazaki Y, Sugawara K, Tsuda F, Takahashi M, Nishizawa T, Okamoto $\mathrm{H}$ : Possible risk factors for the transmission of hepatitis $\mathrm{E}$ virus and for the severe form of hepatitis E acquired locally in Hokkaido, Japan. J Med Virol 2005;76:341-349.

>31 Ohnishi S, Kang JH, Maekubo H, Arakawa T, Karino Y, Toyota J, Takahashi K, Mishiro S: Comparison of clinical features of acute hepatitis caused by hepatitis E virus (HEV) genotypes 3 and 4 in Sapporo, Japan. Hepatol Res 2006;36:301-307. 